too sketchy a fashion to be really useful. Process control concepts and nomenclature are in general less obvious and less readily grasped than those of position control, and the introductory sections of the book create the impression that more effort could usefully have been devoted to elucidation and clear statement. The book does, however, give a comprehensive presentation of the process control problem.

The third book, entitled "An Introduction to the Theory of Control in Mechanical Engineering", does, in fact, draw most of its illustrations from mechanical engineering practice; but the treatment is quite general, and electrical elements and concepts are introduced wherever they are useful or appropriate. A particularly valuable feature of this book is the co-ordination of the analysis of systems in terms of transient response with that in terms of harmonic response. Both analyses are developed in a clear and straightforward fashion, and simple statements of their fundamental mathematical bases are given in two appendixes. The treatment proceeds from a study of typical simple systems to the consideration of general transfer functions and control sequences, and finally to graphical methods for the determination of stability and overall response. The book gives an exceptionally well-balanced introduction to the theory of servo systems, and in scope and presentation it is well adapted to the use of undergraduate students.

The other two text-books, although both starting from elementary considerations, have more specialized aims, and they are better suited to the reader whose branch of specialization is already determined. J. Greig

\section{COMPARATIVE PHYSIOLOGY OF LOWER ANIMALS}

A Physiological Approach to the Lower Animals By J. A. Ramsay. Pp. ix +148 . (Cambridge: At the University Press, 1952.) 15s. net.

TN this interesting and stimulating book Dr. J. A.

Ramsay discusses a number of the more important aspects of comparative physiology which one would expect to find expounded in a text-book; but, by confining himself to a limited number of wellinvestigated and well-chosen examples, he avoids cluttering up his discussion with that bulk of information by which a text-book often conceals general principles from the beginner. Dr. Ramsay's book is about the physiological processes of living animals, and these are dealt with comparatively, topic by topic, starting with nutrition and ending with behaviour. It is not a text-book, and some important topics are deliberately excluded as unsuitable to the author's purpose. General principles about the working of whole animals are most effectively presented; the physiology of constituent cells is avoided as far as possible. Among many topics discussed in a most lively way may be mentioned the following: the difficulties of digesting plant material in which the protoplasm is enclosed by cellulose walls, methods of trituration, and the breakdown of cellulose by bacteria in the gut; the hydraulic aspects of circulation in the invertebrates, and the functions of the auricles and pericardium; the interplay of musculature and skeleton, including the 'hydrostatic skeleton' of many lower invertebrates as well as the hard skeleton of arthropods and vertebrates. In the final chapter the behaviour of animals is discussed in a manner likely to arouse the spirit of inquiry in not a few of Dr. Ramsay's readers.

The emphasis of the book is on general principles, and therefore on the results of physiological investigation rather than on the means. This may prove a disadvantage to those who have no experience of physiological methods but who understand and accept results more readily when they know how these results have been obtained. There is, for example, a considerable discussion on nervous co-ordination, including the grading of sensation and of motor response. It is theoretically sufficient for this discussion to state that stimulation of a nerve leads to the passage of small potential charges of short duration which travel very quickly. In spite of the diversion which would be created, it might be easier for a student to understand the mechanisms of nervous co-ordination if he was in possession of an elementary picture of the characteristics of the action potential. The presentation of general principles also inevitably leads to some over-simplification : for example, temperature control is stated to be confined to birds and mammals, although it is practised communally by the domestio bee.

These, however, are minor criticisms and will have no validity if the book is used, as it should be, during the first year of a university degree course in zoology. It will, in fact, make excellent reading for a university student's first long-vacation. It should not be used except with a reasonable knowledge of the general zoology and anatomy of many of the types discussed, and will form an excellent companion to these studies; it is therefore only suitable for the most advanced pupils at school. It will prove stimulating and enlivening to all keen teachers of zoology in schools, and not least to those who were trained in less physiological times. There is one obvious mistake in the legend of Fig. 18; apart from this, the book is excellently produced and the text is illustrated with a number of simple and clear diagrams.

\section{J. A. KItChING}

\section{BIRDS OF EAST AFRICA}

\section{Birds of Eastern and North Eastern Africa}

By C. W. Mackworth-Praed and Capt. C. H. B. Grant. (African Handbook of Birds, Series 1, Vol. 1.) Pp. xxv $+836+59$ plates. (London, New York and Toronto: Longmans, Green and Co., Ltd., 1952.) 45s. net.

THIS is the first of two volumes - the second is already in the printers' hands - of a work which will be eagerly welcomed by the many people in the eastern parts of Africa who are interested in the rich and varied bird-life of that continent. It has been written by two authorities of high repute in the subject, and they have surely succeeded in their aim "to give others the book they themselves wanted when they first visited and lived in Africa". The area covered is eastern and north-eastern Africa from (and including) the Sudan to the Zambesi.

The authors have been compiling the information for eighteen years. During that time they have published a stream of papers and notes in the ornithological journals, giving facts that were new or clearing up points of difficulty. This has enabled them to issue their summary in handbook form, avoiding discussion and omitting references. For the field worker this has obvious advantages ; and for 